\title{
CORRESPONDENCE
}

\section{Lawrence Memorial Fund}

SIR,--We should be grateful for space in your columns to draw attention to the establishment of a fund to institute a memorial to Professor A. S. C. Lawrence (for obituary see this issue of Nature, page 70).

Professor Lawrence worked in this department for the past twenty-four years and both his recent colleagues and others whom we have consulted feel that it would be appropriate if the memorial were specifically associated with the University of Sheffield, and, in particular, the Department of Chemistry. Accordingly we hope to set up a fund to provide an award for meritorious work in chemistry by an undergraduate in this department. We hope to contact personally as many as possible of Professor Lawrence's former colleagues and friends but the list of these is very long and it seems likely that we shall miss some. We should be very grateful if people whom we fail to contact but who are interested in contributing would contact one of us for further information.

Yours faithfully,

N. M. Atherton

B. BROCKLEHURST

K. R. JENNINGS

Department of Chemistry,

The University,

Sheffield $S 37 H F$

\section{ESRO On-line}

SIR,--In your leading article devoted mainly to the question of the future of the European Space Research Organization (ESRO), you say that ESRO should aim to support, among other things, "more down to earth activities... such as ... the collecting and cataloguing of information (still sorely neglected in the madcap race for information)" (Nature, 231, 273; 1971). As the officer responsible for the ESRO/ELDO Space Documentation Service, I feel that I must point out that we are already operating one of the foremost and most comprehensive documentation systems, in Europe, if not in the world.

This service is based on the remote console (RECON) interrogation system developed for NASA, and depends on a generous exchange agreement with NASA, which must be given its true value in terms of "winning benefits worth having from the application of space research". In fact the RECON system itself is a prime example of "fall-out" from such research. However, ESRO has not been content with offering the benefits of its advanced documentation service to its own staff. This has now been made available directly to national centres, and consequently industry, through the medium of remote on-line terminals. The system was recently demonstrated at the Society of British Aircraft Constructors, and the installation of a terminal in the UK Technology Reports Centre announced in the press.

Although, as you say in your article, ESRO made in its early days a slow start, I think that this situation has clearly changed, and once again the documentation service itself proves this point, inasmuch as it is now providing an even more comprehensive information base to its users by including not only the half million documents of the NASA file, but almost another half million provided by reports in the metallurgical field (Metals Abstracts), engineering (Engineering Index), and by reports generated in the US Government Research and Development programme. Other files in the chemical field will soon follow.

To my knowledge there is no other on-line information system available, offering such a rich source of knowledge, while at the same time combining the economies of centralized file processing for many users, together with the efficiency of local retrieval operations.

Yours faithfully,

$$
\text { N. E. C. Isotta }
$$

Documentation and

Library Service,

ESRO,

Neuilly-sur-Seine

\section{Aid for Bengal}

SiR,- - You have very rightly reproached the developed nations for the sad condition of Bengal (Nature, 231, 341; 1971). But even more deplorable is the complete lack of understanding for the urgency of the problem by the bureaucratic machinery of the government of developing nations. Press and television have reported that even after two weeks or more the aid received from abroad is still blocked in governmental channels. I agree that the supplies of cholera vaccines and saline solutions were belatedly flown from abroad into India but the bureaucrats in the machinery of Indian government itself are further delaying their delivery to the institutions and hospitals urgently requiring them. It is inexcusable that the bureaucratic machinery of the Indian government itself showed no humane concern for the people for whom the world outside India, especially the United Kingdom, is so concerned.

I certainly support, wholeheartedly, your idea of an international organization such as United Nations, or one of its agencies, being given a lien on worldwide facilities to deal with international disasters, whether they be nature or man made. The present evidence is, however, that the United Nations Refugee Organization has done practically nothing in the case of the Bengal disaster. It would appear to be due to lack of dedicated leadership. Private charity organizations such as Oxfam, War on Want and Christain Aid from abroad and the local relief organizations, similar to the one led by Mother Teresa, on the other hand, have achieved more success in spite of their meagre resources, due solely to their sincere and dedicated leadership.

Yours fainthfully,

\section{K. C. Tripathi}

16 St. John's Way,

Hempton,

Oxford $O X 54 Q R$

\section{Caveat Lector}

SIR,-Whatever their individual feelings may be about changes in the language, I imagine that all scientists disapprove of the introduction of ambiguity where formerly there was none, and furthermore that in most cases there would be general support for the removal of traditional ambiguities, unless these were useful.

Both kinds of ambiguity are illustrated to your disadvantage in Nature of June 18, 1971. The first often results from using (adjective + noun) as (noun) and is now widely disfiguring technical literature in the English language. As one example among many in that issue of Nature, on p. 410 , second paragraph, 